\title{
O ensino contábil no estado de Santa Catarina: as matrizes curriculares dos cursos de graduação em análise
}

\author{
Rodrigo Angonese* \\ Odir Luiz Fank \\ Sabrina do Nascimento*****

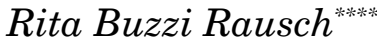

\section{Resumo}

O perfil e a formação do profissional de Ciências Contábeis dependem, em parte, da estrutura curricular oferecida pelas instituições de ensino nos seus cursos de Ciências Contábeis. Diante disso, este estudo tem como objetivo identificar as áreas do conhecimento que contemplam as disciplinas que compõem a matriz curricular dos cursos de Ciências Contábeis oferecidos no estado de Santa Catarina. A metodologia utilizada na pesquisa configura-se como descritiva, conduzida por meio de levantamento documental e de análise quantitativa de dados. Foram analisadas as matrizes curriculares disponibilizadas pelas instituições de ensino superior nos seus sites. A amostra constituiu-se de trinta matrizes curriculares. Os resultados mostraram que do total das disciplinas oferecidas pelas instituições no curso de Ciências Contábeis, 53,13\% estão diretamente relacionadas à área contábil, $10,07 \%$ à área da administração, 8,81\% à área do direito, e com 5,67\% à área da filosofia e da sociologia. As áreas de informática, psicologia, letras e educação não apresentaram uma participação expressiva, mesmo levando em conta sua importância para o profissional de contabilidade.

Palavras-chave: Ensino superior. Ciências Contábeis. Matrizes curriculares.

* Doutor em Ciências Contábeis e Administração pela Universidade Regional de Blumenau. Professor da Universidade de Passo Fundo. E-mail: rangonese@upf.br

** Mestre em Ciências Contábeis pela Universidade Regional de Blumenau. Professor das Faculdades Itapiranga.E-mail: odirfank@hotmail.com

**** Mestre em Ciências Contábeis pela Universidade Regional de Blumenau. Professora do Centro Universitário para o Desenvolvimento do Alto Vale do Itajaí (Unidavi).E-mail: sabnascimento@gmail.com

****** Doutora em Educação pela Unicamp. Professora do Programa de Pós-Graduação em Educação e Ciências Contábeis da FURB. E-mail: rausch@furb.br

http://dx.doi.org/10.5335/rtee.v20i43.4592

Submissão: 12/09/2013. Aceite: 26/06/2014 


\section{Introdução}

Com as exigências que estão sendo impostas pelo mercado, surge a necessidade do processo educacional adequar-se para atender essas necessidades. Para Althoff e Domingues (2008, p. 1), "a necessidade de compreender a complexidade das questões sócio-culturais da atualidade está exigindo um novo tipo de educação que contemple as várias dimensões do ser humano e da sociedade como um todo". As autoras complementam que "[...] o mundo atual demanda profissionais com capacidade cognitiva e com competências sociais de nível elevado, assim como flexibilidade, autonomia, polivalência e disposição para adequação a ocorrências novas". Nesse contexto, as instituições de ensino superior devem estar preocupadas em formar profissionais competentes e competitivos, que saibam desempenhar suas atividades profissionais e que atendam às exigências do mercado de trabalho, adaptando-se facilmente às mudanças.

Nesse sentido, Rosella et al. (2006) destacam que a universidade não tem apenas o papel referente ao ensino das profissões, mas, também, o papel de produzir conhecimentos, capacitar o estudante para fazer questionamentos e críticas, e de responder aos problemas e desafios vivenciados pela sociedade em diferentes momentos. Conforme os autores, destaca-se a necessidade dos futuros profissionais estarem preparados para enfrentar as dificuldades relacionadas à sua profissão, sempre com o intuito de buscar soluções que possam auxiliar nas tarefas diárias. Althoff e Domingues (2008) mencionam que esse preparo para enfrentar as dificuldades relacionadas à profissão, o profissional adquire por meio do conhecimento promovido pela instituição de ensino superior. Dessa forma, a instituição de ensino tem o papel de oferecer meios ao futuro profissional para que esse possa adquirir o conhecimento necessário para atender as necessidades do mercado.

Diante do exposto, surge a seguinte questão-problema deste estudo: quais áreas do conhecimento são contempladas nas disciplinas que compõem a matriz curricular dos cursos de Ciências Contábeis oferecidos no estado de Santa Catarina? Como objetivo geral, este estudo propõe-se a identificar quais áreas do conhecimento são contempladas nas disciplinas que compõem a matriz curricular dos cursos de Ciências Contábeis oferecidos no estado de Santa Catarina.

A justificativa do estudo baseia-se na discussão que ocorre referente às disciplinas que compõem as matrizes curriculares dos cursos de Ciências Contábeis e na pressão exercida pelo mercado sobre as instituições de ensino, objetivando que as IES formem profissionais capazes de responder rapidamente às necessidades impostas sobre a profissão contábil. Baseando-se no exposto, entende-se que 
estudar a composição das matrizes curriculares dos cursos de Ciências Contábeis é importante, pois serão analisadas quais disciplinas compõem as matrizes curriculares, a integração com disciplinas de outras áreas do conhecimento, fundamentais para a formação do profissional.

O estudo está estruturado em cinco seções, incluindo esta introdução. Na segunda seção apresenta-se o referencial teórico dividido em duas partes: o perfil do profissional contábil e as tendências para o ensino da contabilidade no país. A seção três relata os procedimentos metodológicos utilizados. A seção seguinte compreende a apresentação e a análise dos resultados. A seção cinco apresenta as considerações finais, demonstrando os resultados em relação aos objetivos propostos.

\section{Referencial teórico}

O referencial teórico servirá de suporte teórico para a pesquisa, e contempla dois grandes tópicos. O primeiro trata do perfil do profissional contábil, e o segundo trata das tendências do ensino na área contábil e discute a formação das matrizes curriculares dos cursos com disciplinas específicas ou disciplinas de formação complementar.

\subsection{Perfil do profissional contábil}

Houve uma época em que o profissional contábil delimitava sua atuação apenas ao registro e a guarda dos registros contábeis. Porém, novos campos de atuação abriram-se para o bacharel em Ciências Contábeis, devido, principalmente, às mudanças socioeconômicas, que provocaram a ampliação das relações econômicas entre os países, o aumento do número de empresas multinacionais que se instalaram no país, ênfase em relatórios gerenciais com quantidade maior de informações, aumento das exigências legais inseridas no código civil e o maior rigor na prestação de contas, tanto dos sócios quanto da comunidade (FIGUEIREDO; FABRI, 2000).

Marion e Santos (2005, p. 5) afirmam que

[...] hoje, se espera que o contador esteja em constante evolução, e além de uma série de atributos indispensáveis nas diversas especializações da profissão contábil. Não sendo mais possível, sobreviver no momento atual com aquela postura de escriturador, guarda-livros, despachante e atividades burocráticas de maneira geral. 
As mudanças do mercado de trabalho exigem que os alunos estejam preparados para tais evoluções, assim como as instituições de ensino que devem preparar seus alunos para atender as exigências impostas, suprindo as necessidades do mercado.

Para Iudícibus (2004, p. 35),

[...] o homem contador põe ordem, classifica, agrega e inventaria o que o homem produtor, em seu anseio de produzir, vai às vezes desordenadamente, amealhando, dando condições a este último para aprimorar cada vez mais a quantidade e a qualidade dos bens produzidos, por meio de obtenção de maiores informações sobre o que conseguiu até o momento.

Figueiredo e Fabri (2000, p. 35) ressaltam que "muito do que hoje é aceito como contabilidade não era reconhecido há 50 anos, e, seguramente, daqui a 50 anos a contabilidade se modificará profundamente em relação ao que é hoje”. Ainda, segundo os autores, o cenário da contabilidade incorpora mudanças nas atitudes sociais, no progresso da tecnologia da informação e na utilização dos novos métodos. Com isso, os autores ressaltam que a contabilidade estaria mudando o seu papel, de sua base voltada para a escrituração, preparação de demonstrativos contábeis, para um papel mais voltado ao gerenciamento e a tomada de decisões.

Marion (2005) menciona que a contabilidade é a linguagem dos negócios e que as funções do profissional de contabilidade envolvem a coleta de dados, registro dos dados e processamento, geração de relatórios para os usuários utilizarem no processo de tomada de decisão. O profissional da contabilidade é "aquele que faz parte da decisão, que auxilia outros a tomarem decisões, o que significa trabalhar juntamente com uma gama variada de outros profissionais" (SERRA NEGRA, 2004, p. 12).

O conhecimento adquirido pelo aluno no ensino superior, somado com suas habilidades e experiência pessoal acumulada no decorrer dos anos, permite ao graduado em Ciências Contábeis escolher a área em que pretende atuar profissionalmente. Conforme a resolução 560 do Conselho Federal de Contabilidade (CFC), em seu art. $4^{\circ}$, estabelece que

[...] o contabilista pode exercer as suas atividades na condição de profissional liberal ou autônomo, de empregado regido pela CLT, de servidor público, de militar, de sócio de qualquer tipo de sociedade, de diretor ou de conselheiro de quaisquer entidades, ou, em qualquer outra situação jurídica definida pela legislação, exercendo qualquer tipo de função. Essas funções poderão ser as de analista, assessor, assistente, auditor, interno e externo, conselheiro, consultor, controlador de arrecadação, controller, educador, escritor ou articulista técnico, escriturador contábil ou fiscal, executor subordinado, fiscal de tributos, legislador, organizador, perito, pesquisador, planejador, professor ou conferencista, redator, revisor. 
Percebe-se, na resolução 560, que o profissional contábil tem uma vasta opção de perspectivas que podem ser seguidas. Figueiredo e Fabri (2000, p. 41) destacam que o profissional da contabilidade deve manter-se em permanente atualização e que "a aquisição do conhecimento ao longo da vida profissional é direcionada aos interesses e especializações particulares”. Os autores afirmam que há a necessidade do profissional contábil em adquirir conhecimentos que excedem aqueles relacionados aos assuntos profissionais. Recomendam também a atualização com as mais recentes tecnologias, arte, música, política, costumes e hábitos de outros povos, entre outras áreas.

Berti (2001) também destaca a necessidade de conhecimentos complementares além daqueles relacionados à área contábil. $\mathrm{O}$ autor menciona que para o profissional que está ligado a auxiliar as empresas na área de gestão, conhecimentos de administração, economia, direito, humanas e contabilidade são desejáveis. Nota-se, portanto, que para um profissional ter uma visão holística das organizações e poder opinar a respeito, atuar no processo de tomada de decisão, há a necessidade do mesmo apresentar uma gama de conhecimentos que extrapolam os conhecimentos contábeis.

O profissional contábil que buscar essas habilidades interdisciplinares estará preparado para a sua atividade diária, visto que, o mercado atualmente seleciona seus colaboradores por meio de exigências, não apenas de conhecimento técnico e científico, mas, também, buscam profissionais dinâmicos, capazes de apresentar novas soluções e adaptados às mudanças que ocorrem no meio.

\subsection{Tendências para o ensino da contabilidade}

O desafio do ensino superior é socializar o conhecimento. Para alcançar esse objetivo, necessita-se de um ambiente que proporcione e estimule o espírito crítico e criativo, novos questionamentos e proposições (CAPACCHI et al., 2007).

Oliveira (2003, p. 30) menciona que

[...] o ensino da contabilidade deve ter como propósito prover a tomada de decisão considerando os recursos escassos, incluindo a identificação de decisões cruciais das áreas e a determinação de objetivos e metas; fornecer subsídios à direção e controle efetivo de recursos humanos e materiais; prover relatórios gerenciais sobre o custo de recursos com identificação dos pontos críticos e oportunidades de melhoria; facilitar o controle e a função social.

Assim, percebe-se que o ensino na área contábil deve ir além do domínio da técnica. Deve prover o aluno de um senso crítico e proativo para a resolução de problemas. Para isso, precisa compreender a realidade que o circunda, devendo o conhecimento técnico ser articulado com outras áreas do saber. 
O parecer CNE/CES 10/2004, quando menciona o curso de graduação em Ciências Contábeis, no seu art. $4^{\circ}$, determina que o profissional deve revelar a competência e a habilidade de "demonstrar visão sistêmica e interdisciplinar da atividade contábil". Para isso, torna-se necessário que o curso contemple em sua matriz curricular disciplinas afins, que tratem de outras áreas, além da contabilidade.

Watson et al. (2005) mencionam que um ponto relevante do curso de graduação é a matriz curricular, pois quando há uma relação positiva entre as matrizes curriculares e as características do curso escolhido pelo aluno, ocorre uma melhor formação profissional desse universitário. Os autores ressaltam que essa relação positiva entre as matrizes curriculares e as características do curso, tornam-se mais importantes nas áreas de negócios, como a contabilidade, pois o aluno precisa obter o conhecimento técnico da sua área de formação, mas também ter um conhecimento de outras áreas que possam auxiliá-lo na sua atividade profissional.

Nesse ponto, a instituição de ensino superior precisa assumir seu papel, pois tem responsabilidade na formação profissional dos indivíduos do presente e do futuro. É ela que tem como atribuição socializar os conhecimentos necessários ao desenvolvimento humano e científico e, para tal, necessita ter compromisso e participação nos assuntos atuais, bem como manter estreita relação entre teoria e prática.

Para Porto e Régnier (2003, p. 9), "a educação agrega valor aos sistemas produtivos ao mesmo tempo em que se torna um valor superlativo de humanidade e do grau de civilidade e de desenvolvimento de um país". Conforme os autores, com a educação, toda a sociedade tem incrementos, pois, com pessoas instruídas, ocorre discussão de ideias, promovendo melhorias.

Com o intuito de auxiliar nesse processo da educação, a instituição de ensino superior precisa oferecer um ambiente propício para o conhecimento. Paviani e Pozenato (1984, p. 14) ressaltam que "a convivência universitária, o espírito universitário, o intercâmbio de experiências e conhecimentos entre as pessoas, é tão importante quanto às atividades docentes e de pesquisa, tão decisivo para a formação dos indivíduos quanto às bibliotecas e os laboratórios".

Para buscar atender os fins a que os cursos de graduação se propõem, as instituições de ensino utilizam como referência as Diretrizes Curriculares Nacionais (DCN), que foram homologadas em 16 de dezembro de 2004. Em relação aos cursos de graduação em Ciências Contábeis, as Diretrizes Curriculares Nacionais apresentam as competências e as habilidades desejadas para o formando nessa área: 
I - utilizar adequadamente a terminologia e a linguagem das Ciências Contábeis e Atuariais;

II - demonstrar visão sistêmica e interdisciplinar da atividade contábil;

III - elaborar pareceres e relatórios que contribuam para o desempenho eficiente e eficaz de seus usuários, quaisquer que sejam os modelos organizacionais;

IV - aplicar adequadamente a legislação inerente às funções contábeis;

V - desenvolver, com motivação e através de permanente articulação, a liderança entre equipes multidisciplinares para a captação de insumos necessários aos controles técnicos, à geração e disseminação de informações contábeis, com reconhecido nível de precisão;

VI - exercer suas responsabilidades com o expressivo domínio das funções contábeis, incluindo noções de atividades atuariais e de quantificações de informações financeiras, patrimoniais e governamentais, que viabilizem aos agentes econômicos e aos administradores de qualquer segmento produtivo ou institucional o pleno cumprimento de seus encargos quanto ao gerenciamento, aos controles e à prestação de contas de sua gestão perante a sociedade, gerando também informações para a tomada de decisão, organização de atitudes e construção de valores orientados para a cidadania;

VII -desenvolver, analisar e implantar sistemas de informação contábil e de controle gerencial, revelando capacidade crítico analítica para avaliar as implicações organizacionais com a tecnologia da informação;

VIII - $\quad$ exercer com ética e proficiência as atribuições e prerrogativas que lhe são prescritas através da legislação específica, revelando domínios adequados aos diferentes modelos organizacionais (MEC, 2004, p. 2).

Com as Diretrizes Curriculares Nacionais, o Ministério da Educação (MEC) estabelece as competências e as habilidades desejadas para o formando em Contabilidade. Percebe-se que as diretrizes apresentam critérios em relação às competências, como também critérios de interdisciplinaridade e ética.

Em relação ao ensino de contabilidade no Brasil, Venturi et al. (2008, p. 2) mencionam que

[...] as atividades didáticas de ensino da Contabilidade no Brasil tiveram início no começo do século XIX, sendo que era caracterizado como essencialmente técnico. Nessa época era muito comum a figura do guarda livros, numa abordagem pragmática, sendo que em termos acadêmicos as disciplinas de contabilidade eram ministradas em outros cursos, pois não se tinha um curso regulamentado de Ciências Contábeis na época.

No que diz respeito ao curso de Ciência Contábil e Atuariais, de acordo com Rosella et al. (2006, p. 29), "foi instituído pelo Decreto-lei n. 7.988, de 22 de setembro de 1945, com duração de quatro anos, concedendo o título de bacharel em Ciências Contábeis para aqueles que o concluíssem". Os autores destacam que pela lei n. 1.401, de 31 de julho de 1951, foram criados dois novos cursos, um de Ciências Contábeis e outro de Ciências Atuariais. 
No estado de Santa Catarina, segundo Schlindwein (2007), os primeiros cursos de graduação em Ciências Contábeis foram implantados na Universidade Federal de Santa Catarina (UFSC), em 1965, por meio do parecer 39/SESU/MEC/65, de 8 de fevereiro de 1965.

Principalmente a partir da década de 2000, ocorreu um crescimento considerável no número de instituições de ensino superior no país. Diversas discussões foram desenvolvidas acerca da matriz curricular do curso de Ciências Contábeis. Alguns autores defendem que a matriz deveria conter mais disciplinas específicas, tornando o mesmo técnico, enquanto outros autores defendem que a matriz deveria focar na presença de outras disciplinas afins à contabilidade. A seguir, esses temas serão abordados.

\subsubsection{Disciplinas específicas}

As matrizes curriculares, em sua maioria, são elaboradas conforme as diretrizes ministeriais em termos do conteúdo mínimo a ser cursado em cada período letivo. Alguns autores discutem essa forma de elaborar as matrizes, pois falhas ocorrem. Entre as falhas mais citadas pelos autores, pode-se destacar que não deveríamos ter um currículo com o mesmo formato em regiões distintas de um país com tantas diversidades econômicas. A segunda, diz respeito ao grande número de disciplinas de outras áreas, que se apresentam em volume muito expressivo em detrimento as disciplinas específicas da área contábil (CAPACCHI et al., 2007).

Em relação à primeira falha mencionada, Serra Negra (2004, p. 13) afirma que "sociedades diferentes exigem comportamentos diferentes. Portanto, a educação contábil em cada instituição tem que levar em consideração os conjuntos de valores de cada lugar".

Quanto à segunda falha mencionada, a qual diz respeito ao grande número de disciplinas de outras áreas, que se apresentam em volume muito expressivo em detrimento a disciplinas específicas da área contábil. Capacchi et al. (2007) mencionam que cursos como de Agronomia, Medicina, Fisioterapia, Medicina Veterinária e Direito, dentre outros, são direcionados para enfatizar a prática profissional. Os alunos desses cursos iniciam a prática profissional já nos primeiros semestres. Os autores ressaltam que nos cursos de Ciências Contábeis, na sua maioria, a prática quando existe, restringe-se a um ou dois semestres em um laboratório de informática e, em alguns casos, os alunos participam de Empresas Júnior ao final do curso. Essa pouca relação entre teoria e prática pode causar dificuldades aos alunos quando esses se inserirem no mercado, pois não estarão preparados, na prática, para exercer as funções exigidas. 
Para Serra Negra (2004), o fato de a maioria dos estudantes de graduação estudar no período noturno e trabalhar durante o dia limita a possibilidade de maior aprendizado, pois, em muitos casos, os estudantes chegam cansados nas salas de aula e com pouca motivação, tornando as aulas pouco proveitosas. Para Serra Negra $(2004$, p. 11$)$,

[...] segundo inúmeras pesquisas do ensino contábil, o perfil discente do Curso Superior de Ciências Contábeis no Brasil aponta, em sua maioria absoluta, para adultos na faixa etária acima de 23 anos que estudam no turno noturno em virtude de trabalharem durante o dia. Dessa forma, o processo de formação dos alunos em Ciências Contábeis pressupõe a utilização de metodologias ativas de ensino-aprendizagem que coloquem o professor como facilitador e orientador desse processo.

Dentre as críticas mais frequentes em relação aos cursos de Ciências Contábeis destaca-se que esses apresentam um caráter excessivamente teórico e, assim, não preparam o aluno para a atividade profissional (SERRA NEGRA, 2004). O autor ressalta que cabe aos coordenadores, professores e alunos encontrarem uma forma que possibilite ajustar as matrizes curriculares, com o intuito de relacionar tanto o conhecimento teórico quanto o prático.

Laffin (2001, p. 25) destaca que "a formação dos bacharéis em Ciências Contábeis, apesar de contemplar outras áreas do conhecimento em seu currículo, é eminentemente técnica e não abriga uma preocupação de formação ampla, preocupando-se mais com a técnica de registro e controle isolados". Deve existir uma preocupação na formação do aluno, tanto para o mercado de trabalho, como também para formar cidadãos que possam contribuir com seus princípios para o bem da sociedade em geral. Oliveira (2003, p. 30) menciona que o "desafio é captar as mudanças no mercado para que se tenha eficácia no ensino da Contabilidade [...]. Mudanças no ambiente econômico e na tecnologia têm superado a educação contábil e levado ao aumento da lacuna entre as necessidades atuais e o ensinamento contábil".

Essa preocupação também é demonstrada por Figueiredo e Fabri (2000, p. 37) ao mencionarem que "o enfoque tradicional da educação em contabilidade tem sido o de focalizar os ensinamentos quase que totalmente nos procedimentos de contabilização dos dados contábeis". Essa abordagem resulta, segundo os autores, em uma restrição ao objetivo da contabilidade e impede o reconhecimento das mudanças sociais e econômicas que tornam obsoletas muitas práticas adotadas. Assim, destaca-se a importância de um currículo que forme um profissional habilitado a perceber e adaptar-se às mudanças. O parecer CNE/CES 67 (2003, p. 7), também alerta a esse respeito e menciona que "não se cogita mais o profissional 'preparado', mas o profissional apto às mudanças e, portanto, adaptável”. 
Oliveira (2003, p. 31) menciona que é necessário que os profissionais de contabilidade

[...] rompam esses limites, de forma a atuar como gestores de todas informações das organizações, incluindo as relações com fornecedores, clientes, funcionários, com a sociedade e com os processos internos. A esses elementos chamamos de condições necessárias, pois são essenciais para atingir com consistência os resultados financeiros.

Percebe-se, dessa forma, que são exigidas competências do profissional da contabilidade que envolvem uma gama de conhecimentos variados, de diversas áreas, e que os currículos oferecidos pelas instituições, na medida do possível, devem atender a essa necessidade de mercado.

\subsubsection{Disciplinas de formação complementar}

Na área das Ciências Sociais Aplicadas, como Administração e Contabilidade, a interdisciplinaridade é um instrumento capaz de unir disciplinas com conteúdos específicos ou generalizados, como também pode basear-se em uma formação que atenda a níveis básicos, intermediários e avançados, relacionando, de uma forma geral, a teoria com a prática. A interdisciplinaridade, no curso de Ciências Contábeis, nem sempre é observada de forma explícita dentro da matriz curricular e nas ementas do curso, principalmente na relação entre as disciplinas, no que diz respeito às pesquisas publicadas sobre o assunto (JANTSCH; BIANCHETTI, 2004).

Miranda e Miranda (2006) apresentam duas razões para se adotar a interdisciplinaridade. A primeira é a globalização, a partir da fusão das áreas afins; a segunda é superação da fragmentação do conhecimento, ou seja, a impressão que o discente tem de estudar algo distinto das demais áreas, como também do docente considerar à sua disciplina a mais importante, passando essa visão aos alunos.

Assim, Jantsch e Bianchetti (2004, p. 198) esclarecem que

[...] o interdisciplinar está se estabelecendo, hoje, não porque os homens decidiram, mas sim pela pressão, pelas necessidades colocadas pela materialidade do momento histórico. A materialidade histórica exige a presença da ciência e da tecnologia em qualquer espaço de atuação e de possível colaboração da universidade, seja no sentido instrumental ou no sentido da criação.

Araújo, Araújo e Moraes Júnior (2009) ressaltam que o profissional contábil necessita de conhecimentos diversos, como por exemplo, de psicologia, sociologia, filosofia, direito, administração e economia, para que ele possa perceber outras áreas das Ciências Humanas, como também das Ciências Sociais Aplicadas, da qual a contabilidade faz parte. 
O próprio parecer CNE/CES 10 (2004, p. 3) no art. 8o estabelece a necessidade da interdisciplinaridade nos cursos de graduação em Ciências Contábeis por meio de atividades complementares.

[...] as Atividades Complementares são componentes curriculares que possibilitam o reconhecimento, por avaliação, de habilidades, conhecimentos e competências do aluno, inclusive adquiridas fora do ambiente escolar, abrangendo a prática de estudos e atividades independentes, transversais, opcionais, de interdisciplinaridade, especialmente nas relações com o mundo do trabalho e com as ações de extensão junto à comunidade.

O parecer complementa-se, afirmando que as atividades complementares constituem-se componentes curriculares enriquecedores e implementadores do próprio perfil do formando.

Por ser um tema bastante relevante e que gera discussão, a interdisciplinaridade vem sendo utilizada em pesquisas científicas, "alimentando" a discussão em relação à sua aplicação ou não. Padoan e Clemente (2006), em seu estudo, analisaram a possibilidade de percepção de alguns pontos de interdisciplinaridade, principalmente no final do curso, que aumenta o número de disciplinas aplicáveis e mais direcionadas à área. Os autores verificaram que o professor é fundamental como facilitador desse processo de interdisciplinaridade, pois ele pode disponibilizar conteúdos e técnicas atualizadas, promovendo a harmonização das disciplinas, alinhado com as necessidades e com as mudanças que o mercado exige.

\section{Procedimentos metodológicos}

Quanto à classificação metodológica, esta pesquisa, no que se refere aos seus objetivos, classifica-se como descritiva. Para Roesch (1999, p. 130),

[...] se o propósito do projeto é obter informações sobre determinada população: por exemplo, contar quantos, ou em que proporção seus membros tem certa opinião ou característica, ou com que frequência certos eventos estão associados entre si, a opção é utilizar um estudo de caráter descritivo.

Quanto aos procedimentos, a pesquisa foi classificada como documental. Gil (1999) menciona que a pesquisa documental baseia-se em materiais que ainda não receberam um tratamento analítico ou que podem ser reelaborados de acordo com os objetivos da pesquisa. Silva e Grigolo (2001) contribuem, mencionando que a pesquisa documental vale-se de materiais que ainda não receberam nenhuma análise aprofundada. Esse tipo de pesquisa visa selecionar, tratar e interpretar a informação 
bruta, buscando extrair dessa algum sentido e introduzir-lhe algum valor, podendo, desse modo, contribuir com a comunidade científica, a fim de que outros possam voltar a desempenhar futuramente o mesmo papel (SILVA; GRIGOLO, 2001).

Quanto à abordagem do problema, classificou-se a pesquisa como quantitativa. Nesta pesquisa não houve emprego de quantificação na etapa da coleta das informações, mas houve o emprego da quantificação no tratamento das informações coletadas, caracterizando-a como quantitativa. Richardson (1989, p. 29) comenta que:

[...] o método quantitativo, como o próprio nome indica, caracteriza-se pelo emprego da quantificação tanto nas modalidades de coleta de informações, quanto no tratamento dessas, através de técnicas estatísticas, desde as mais simples, como percentual, média, desvio-padrão, às mais complexas, como coeficiente de correlação, análise de regressão, etc.

A população objeto do estudo foi selecionada junto ao web site do Ministério da Educação, composta pelo total dos cursos de ensino superior em Ciências Contábeis oferecidos no estado de Santa Catarina. Optou-se pelos cursos oferecidos na modalidade presencial. $\mathrm{O}$ total de cursos ofertados, conforme consulta realizada na data de 23 de outubro de 2010, foi de 49 cursos.

Relacionados os cursos, o segundo passo foi consultar os web sites das instituições com o objetivo de obter as matrizes curriculares dos cursos. Para as instituições que ofereciam o mesmo curso em diferentes campi, foi considerada a estrutura curricular do campus sede. Nem todos os cursos disponibilizavam a matriz curricular online. Ao final da consulta, foram encontradas trinta matrizes curriculares que constituíram a amostra para a pesquisa.

Obtidas as matrizes curriculares, as informações sobre as disciplinas foram tabuladas em planilha eletrônica e analisadas por frequência absoluta. Foram consideradas todas as disciplinas que constavam nas matrizes curriculares, independente de classificarem-se como obrigatórias ou optativas. Não foram levadas em consideração as ementas de cada disciplina nem a carga horária, visto que nem todas as matrizes curriculares disponibilizadas ofereciam essas informações. As disciplinas foram agrupadas, por afinidade, em 15 grandes áreas.

\section{Apresentação e análise dos resultados}

Objetivando-se analisar as matrizes curriculares dos cursos de Ciências Contábeis oferecidos no estado de Santa Catarina, demonstra-se por meio do Quadro 1 as áreas e o total de disciplinas atribuídas a cada área. 
Quadro 1 - Distribuição das disciplinas por área

\begin{tabular}{|l|c|c|}
\hline \multicolumn{1}{|c|}{ Grande área } & Número de disciplinas & Percentual sobre total (\%) \\
\hline Contabilidade & 712 & 53,13 \\
Administração & 135 & 10,07 \\
Direito & 118 & 8,81 \\
Social & 76 & 5,67 \\
Economia & 76 & 5,67 \\
Matemática & 63 & 4,70 \\
Pesquisa & 40 & 2,99 \\
Estatística & 38 & 2,84 \\
Linguística & 32 & 2,39 \\
Psicologia & 23 & 1,72 \\
Informática & 13 & 0,01 \\
Línguas estrangeiras & 10 & 0,00 \\
Educação Física & 2 & 0,00 \\
Educação & 1 & 0,00 \\
História & 1 & 0,00 \\
Total & 1.340 & 100,00 \\
\hline
\end{tabular}

Fonte: dados primários.

Analisando-se as informações constantes no Quadro 1, percebe-se que o maior número de disciplinas refere-se àquelas relacionadas à grande área da Contabilidade. Não poderia ser diferente, visto que, as disciplinas analisadas foram obtidas dos currículos do curso de Ciências Contábeis. Porém, cabe destacar que muito embora o curso seja de Ciências Contábeis, 53,13\% constituem disciplinas diretamente relacionadas ao curso e, aproximadamente metade do curso corresponde a disciplinas afins, pertencentes a outras áreas acadêmicas e que objetivam complementar a formação do profissional contábil, dotando-o de uma visão mais abrangente em relação ao contexto em que o profissional irá desempenhar suas funções.

O currículo do curso de Ciências Contábeis é enriquecido pelas contribuições de outras áreas científicas. A primeira área que mais contribui é a de Administração, com 10,07\% do total das disciplinas, até porque, a administração faz parte da mesma grande área de cursos afins. Em seguida, aparece a área de Direito com 8,81\%. A área social que inclui disciplinas ligadas à Filosofia e à Sociologia, e assuntos relacionados à responsabilidade social e ambiental aparecem em terceiro lugar junto com a área da Economia. $O$ fato de a área social estar na terceira posição, somente atrás das áreas de Administração e Direito e na frente de outras importantes áreas do conhecimento, revela a preocupação das instituições de ensino em oferecer um programa que priorize questões ligadas ao comportamento humano na sociedade. Uma das razões para essa área se destacar entre as demais pode advir da pressão social 
e do mercado de trabalho, que valoriza qualidades ligadas ao comportamento ético e socialmente responsável nas organizações. Ressalta-se que há pouca disponibilidade de disciplinas de línguas, tanto da língua portuguesa quanto de língua estrangeira.

Empatada no número de disciplinas com a área social, aparece à área da Economia e, logo na sequência, com 4,7\% das disciplinas, encontra-se a área da matemática. As áreas da pesquisa e da estatística aparecem com 2,99\% e 2,84\%, respectivamente.

As demais áreas somadas respondem por $6,12 \%$ das disciplinas consultadas. Entre essas áreas, chama a atenção disciplinas oferecidas no curso de Ciências Contábeis relacionadas à educação e à história, áreas que na concepção dessas instituições também podem colaborar para a formação do profissional contábil. Outro fator que vale destacar é a baixa participação de disciplinas ligadas à informática, à psicologia e à língua estrangeira. A informática constituiu-se como uma área que alavancou o potencial da contabilidade por tratar dados e gerar relatórios das informações. A Psicologia torna-se fundamental para a Contabilidade, pois auxilia 0 profissional a entender fenômenos ligados ao comportamento organizacional.

Realizado esse apanhado geral dos resultados, descreve-se nos demais quadros, aspectos relacionados a cada grande área. No Quadro 2, demonstra-se a composição das principais disciplinas que compuseram a grande área da contabilidade.

Quadro 2 - Subáreas que compuseram a área da contabilidade

\begin{tabular}{|l|c|c|}
\hline \multicolumn{1}{|c|}{ Subáreas do grupo contabilidade } & Número disciplinas & Percentual sobre o total (\%) \\
\hline Contabilidade societária & 165 & 23,17 \\
Trabalho de conclusão e estágio & 63 & 8,85 \\
Custos & 58 & 8,15 \\
Contabilidade fiscal & 55 & 7,72 \\
Prática contábil e laboratório & 54 & 7,58 \\
Auditoria & 49 & 6,88 \\
Contabilidade gerencial e controladoria & 46 & 6,46 \\
Contabilidade pública & 42 & 5,90 \\
Análise das demonstrações contábeis & 38 & 5,34 \\
Perícia & 29 & 4,07 \\
Tópicos contemporâneos & 27 & 3,79 \\
Teoria da contabilidade & 25 & 3,51 \\
Outras & 21 & 2,95 \\
Contabilidade internacional & 21 & 2,95 \\
Sistemas de informações contábeis & 11 & 1,54 \\
Contabilidade do agronegócio & 8 & 1,12 \\
Total & 712 & 100,00 \\
\hline
\end{tabular}

Fonte: dados primários. 
Pelos dados apresentados no Quadro 2, percebe-se que na área de contabilidade, as disciplinas mais trabalhadas são aquelas relacionadas aos aspectos societários com $23,17 \%$, seguidas pelas disciplinas que tratam do trabalho de conclusão e estágio supervisionado, com $8,85 \%$. Destacam-se nesse grupo, as disciplinas ligadas à prática contábil e laboratório, e disciplinas ligadas a aspectos práticos das atividades do profissional contábil no seu dia a dia. Percebe-se a preocupação das instituições em formar um profissional que atenda às necessidades do mercado de trabalho.

Destaca-se, também, que a área de contabilidade do agronegócio apresentou apenas oito disciplinas. Considerando que a área agrícola do estado de Santa Catarina é representativa, haveria ainda a necessidade das instituições oferecerem maior oportunidade aos alunos para capacitação nessa área.

No Quadro 3 demonstra-se a grande área das disciplinas da administração, divididas por subáreas, definidas pelo agrupamento das disciplinas, conforme a afinidade entre essas.

Quadro 3 - Subáreas que compuseram a área da administração

\begin{tabular}{|l|c|c|}
\hline \multicolumn{1}{|c|}{ Subáreas do grupo administração } & Número de disciplinas & Percentual sobre o total (\%) \\
\hline Administração financeira & 30 & 22,22 \\
Gestão de negócios & 22 & 16,30 \\
Orçamento empresarial & 20 & 14,81 \\
Teoria geral da administração & 17 & 12,59 \\
Empreendedorismo & 13 & 9,63 \\
Jogos de empresa & 8 & 5,93 \\
Marketing & 6 & 4,44 \\
Administração de recursos humanos & 5 & 3,70 \\
Sistemas de informação & 5 & 3,70 \\
Estratégia & 4 & 2,96 \\
Outras & 4 & 2,96 \\
Administração de materiais & 1 & 0,76 \\
Total & 135 & 100,00 \\
\hline
\end{tabular}

Fonte: dados primários.

Analisando as informações constantes no Quadro 3, percebe-se que as disciplinas da administração que mais aparecem nos cursos de Ciências Contábeis estão ligadas à área financeira, à gestão de negócios, a orçamento empresarial e à teoria geral da administração. Juntas, essas disciplinas respondem por 65,92\% de todas as disciplinas de administração. 
No Quadro 4, apresenta-se a grande área das disciplinas de Direito, divididas por subáreas, definidas pelo agrupamento das disciplinas, conforme a afinidade entre essas.

Quadro 4 - Subáreas que compuseram a área do Direito

\begin{tabular}{|l|c|c|}
\hline \multicolumn{1}{|c|}{ Subáreas do grupo Direito } & Número de disciplinas & Percentual sobre o total (\%) \\
\hline Direito tributário & 48 & 40,68 \\
Direito do trabalho & 27 & 22,88 \\
Instituições de direito público e privado & 18 & 15,25 \\
Direito Comercial/Societário & 15 & 12,71 \\
Outros & 10 & 8,47 \\
Total & 118 & 100,00 \\
\hline
\end{tabular}

Fonte: dados primários.

Analisando as informações constantes no Quadro 4, percebe-se que os cursos de Ciências Contábeis analisados concentram 40,68\% das disciplinas da área do Direito Tributário. Se somadas as disciplinas relacionadas ao Direito do Trabalho com as disciplinas da área do Direito Tributário, totalizam 63,56\% das disciplinas. Portanto, percebe-se que a ênfase na formação do profissional contábil está concentrada, para a área do Direito, em disciplinas do Direito Tributário e do Trabalho.

No Quadro 5 demonstra-se a grande área social (Ciências Humanas), divididas por subáreas, definidas pelo agrupamento das disciplinas, de acordo com a afinidade entre essas.

Quadro 5 - Subáreas que compuseram a área social

\begin{tabular}{|l|c|c|}
\hline \multicolumn{1}{|c|}{ Subáreas do grupo social } & Número de disciplinas & Percentual sobre o total (\%) \\
\hline Ética & 32 & 42,11 \\
Sociologia & 26 & 34,21 \\
Filosofia & 16 & 21,05 \\
Outras & 2 & 2,63 \\
Total & 76 & 100,00 \\
\hline
\end{tabular}

Fonte: dados primários.

Analisando-se os dados apresentados no Quadro 5, percebe-se a preocupação das instituições em oferecer uma formação que contemple, também, aspectos relacionados à ética, à sociologia e à filosofia, áreas que se preocupam com a relação do ser humano em sociedade. No total, foram encontradas 76 disciplinas relacionadas 
a essa área, igualando ou superando diversas outras áreas do mesmo modo importantes na formação do profissional em ciências contábeis.

O Quadro 6 mostra a grande área da Economia, dividida por subáreas, definidas pelo agrupamento das disciplinas, conforme a afinidade entre essas.

Quadro 6 - Subáreas que compuseram a área social

\begin{tabular}{|l|c|c|}
\hline Subáreas do grupo economia & Número de disciplinas & Percentual sobre o total (\%) \\
\hline Economia Geral & 40 & 52,63 \\
Mercado de capitais & 20 & 26,32 \\
Análise de investimentos & 13 & 17,11 \\
Outras & 3 & 3,95 \\
Total & 76 & 100,00 \\
\hline
\end{tabular}

Fonte: dados primários.

A partir das informações constantes no Quadro 6, percebe-se que a maior parte das disciplinas que tratam de economia no curso de Ciências Contábeis classificam-se como disciplinas de Economia Geral. Nesse grupo, encontram-se disciplinas que foram nominadas como Economia I e II, Microeconomia, Macroeconomia, Economia Brasileira, Fundamentos de Economia, Introdução à Economia, etc. Portanto, entende-se que são disciplinas que abordam aspectos fundamentais da economia aplicados à contabilidade. De modo mais específico, em segundo lugar, aparece o subgrupo de disciplinas da economia, ligados por afinidade ao assunto mercado de capitais. As disciplinas que tratam sobre análise de investimento aparecem em terceiro lugar com $17,11 \%$ do total.

No Quadro 7, apresenta-se as grandes áreas de Matemática, Pesquisa, Estatística, Linguística e Psicologia, divididas por subáreas, definidas pelo agrupamento das disciplinas, segundo a afinidade entre essas. 
Quadro 7 - Subáreas da matemática, pesquisa, estatística e linguística

\begin{tabular}{|l|c|c|}
\hline \multicolumn{1}{|c|}{ Grupos e subgrupos } & Número de disciplinas & Percentual sobre o total (\%) \\
\hline Matemática & & 46,03 \\
$\quad$ Matemática fundamental & 29 & 53,97 \\
Matemática financeira & 34 & 100,00 \\
Total matemática & 63 & 100,00 \\
Pesquisa & 40 & \\
$\quad$ Metodologia científica & & 78,95 \\
Estatística & 30 & 21,05 \\
Fundamentos de estatística & 8 & 100,00 \\
$\quad$ Métodos quantitativos & 38 & \\
Total estatística & 17 & 53,13 \\
Linguística & 6 & 18,75 \\
$\quad$ Comunicação e expressão & 9 & 28,13 \\
Leitura, interpretação e produção & 32 & 100,00 \\
de textos & & \\
Português & & \\
Total da linguística & & \\
\hline
\end{tabular}

Fonte: dados primários.

Pelas informações constantes no Quadro 7, entende-se que a abordagem matemática nos cursos de Ciências Contábeis restringe-se a Matemática Fundamental e a Financeira. Como acontece nas demais subáreas, percebe-se que alguns cursos optam por oferecer duas disciplinas das subáreas nos cursos, enquanto que outros optam por oferecer apenas uma disciplina.

Na subárea de pesquisa, optou-se por concentrar todas as disciplinas sob uma mesma terminologia. Na subárea de estatística, todos os cursos analisados oferecem uma disciplina sob essa temática, enquanto que outros oferecem também alguma disciplina relacionada a métodos quantitativos.

$\mathrm{Na}$ área da linguística, percebe-se que prevalecem três disciplinas, sendo que a mais comum é aquela que se relaciona com a comunicação e expressão. Com menor ênfase, aparecem também disciplinas relacionadas à língua portuguesa e à leitura, à produção e à interpretação de texto. Em relação à área da linguística, nota-se que poucas instituições de ensino oferecem disciplinas de língua estrangeira.

Disciplinas relacionadas à leitura, à interpretação e à produção de textos, bem como relacionadas à língua portuguesa, são importantes para a formação do profissional contábil, pois sua rotina é regulada por leis, normas e regulamentos que dependem de correta interpretação e escrita. Diante disso, recomenda-se pesquisas 
futuras para investigar os motivos que levam à baixa oferta de disciplinas relacionadas a essa temática.

As outras subáreas (Psicologia, Informática, Línguas Estrangeiras, Educação Física, Educação, História) não foram detalhadas devido à baixa representação demonstrada no Quadro 1. Entretanto, pesquisas futuras também podem investigar os motivos da baixa representatividade de disciplinas ligadas à informática e à psicologia, áreas que o profissional contábil depende para exercer suas atividades com êxito.

O Conselho Federal de Contabilidade (CFC) publicou em 2009 a proposta nacional de conteúdo para o curso de Ciências Contábeis. Nesse documento, é sugerido um conjunto de disciplinas para o curso, contemplando a formação básica, a formação profissional, a formação teórico-prática, inclusive com sugestão para a inserção de disciplinas optativas. Para aprofundar a análise dos dados, o Quadro 8 apresenta a classificação das disciplinas nas mesmas áreas identificadas no Quadro 1.

Quadro 8 - Classificação das disciplinas da proposta nacional de conteúdo para o curso de Ciências Contábeis nas subáreas selecionadas para a pesquisa

\begin{tabular}{|l|c|c|}
\hline \multicolumn{1}{|c|}{ Grande área } & Número de disciplinas & Percentual sobre total (\%) \\
\hline Contabilidade & 22 & 47,83 \\
Administração & 5 & 10,87 \\
Direito & 4 & 8,70 \\
Social & 3 & 6,52 \\
Economia & 4 & 8,70 \\
Matemática & 2 & 4,35 \\
Pesquisa & 2 & 4,35 \\
Estatística & 1 & 2,17 \\
Linguística & 1 & 2,17 \\
Psicologia & 1 & 2,17 \\
Informática & 1 & 2,17 \\
Línguas estrangeiras & 0 & 0,00 \\
Educação Física & 0 & 0,00 \\
Educação & 0 & 0,00 \\
História & 0 & 0,00 \\
Total & 46 & 100,00 \\
\hline
\end{tabular}

Fonte: dados primários. 
Pelos dados que constam no Quadro 8, quando comparados com os dados apresentados no Quadro 1, percebe-se que as grades curriculares analisadas nesta pesquisa apresentam um perfil muito semelhante àquele recomendado pelo Conselho Federal de Contabilidade. Chama a atenção, de modo geral, que as grades analisadas conferem um peso maior para as disciplinas específicas da área da Contabilidade, superando em 5,3 pontos percentuais a recomendação do CFC. Outra área que cabe destacar é a Economia. As disciplinas da área de Economia representam $5,67 \%$ da grade curricular, enquanto que o Conselho Federal de Contabilidade recomenda $8,7 \%$. As demais áreas não apresentam diferenças significativas entre o encontrado nesta pesquisa e o recomendado pelo Conselho, o que revela uma harmonização entre o recomendado pelo CFC e o praticado pelas instituições de educação superior.

\section{Considerações finais}

O profissional da área contábil necessita de conhecimentos específicos de outras áreas do conhecimento para exercer suas atividades. Conhecimentos referentes à administração, ao direito, à ética, à sociologia, à língua portuguesa, à estatística e à economia fundamentais para que o profissional consiga compreender e atuar no ambiente em que está inserido. Considerando esse contexto, este estudo teve como objetivo identificar as disciplinas que compõem a matriz curricular dos cursos de Ciências Contábeis oferecidos no estado de Santa Catarina e obter um panorama de tais disciplinas, que estão sendo oferecidas aos alunos, das mais diversas áreas do conhecimento.

Os resultados da pesquisa mostraram que do total das disciplinas relacionadas, 53,13\% referem-se diretamente à área contábil. As demais, estão divididas entre as diversas áreas do conhecimento que interessam o profissional de contabilidade. A área que mais se destaca na formação do profissional contábil, exceto a contábil, é a administração com 10,07\% do total, seguida pela área do direito com $8,81 \%$ e em terceiro lugar a área social que envolve a filosofia, a sociologia e a ética, e a área da economia com $5,67 \%$.

Percebe-se uma preocupação, por parte das instituições, em oferecer uma formação que contemple quesitos éticos, sociais e humanistas. Por outro lado, algumas áreas como a psicologia e a informática não apareceram na mesma proporção de sua importância para o profissional da contabilidade.

Em síntese, o curso de Ciências Contábeis no estado de Santa Catarina busca formar profissionais que, além do conhecimento técnico na área, tenham boas 
noções de administração financeira, gestão de negócios, orçamento empresarial, teoria geral da administração, direito tributário e do trabalho, economia geral, ética, sociologia e filosofia. A proposta nacional de conteúdo para o curso de Ciências Contábeis publicada pelo CFC, também, sugere a inclusão de disciplinas ligadas a outras áreas do conhecimento, destacando a importância da interdisciplinaridade para o profissional da área. Pelos dados da pesquisa, destaca-se que a formação do profissional contábil abrange aproximadamente $47 \%$ do currículo com disciplinas afins. Tendo em vista a ampla gama de assuntos contábeis e afins, e o exíguo tempo de formação, conclui-se que existe a necessidade do profissional contábil continuar seus estudos após a graduação, com investimentos constantes em formação continuada, objetivando especializar-se no ramo da contabilidade em que atua, além de ampliar o conhecimento em áreas afins.

Finalizando, recomendam-se pesquisas para melhor esclarecer os motivos que levam a baixa oferta de importantes disciplinas para o profissional da contabilidade, principalmente aquelas ligadas à área da informática, da psicologia, da linguística, e até mesmo da própria área contábil, como contabilidade do agronegócio.

Também, pesquisa semelhante pode ser realizada considerando os cursos que são oferecidos na modalidade à distância. Ressalta-se que os resultados desta pesquisa limitam-se a amostra analisada e não devem ser generalizados. Os resultados de outras pesquisas podem colaborar para o entendimento desse fenômeno, como pesquisas que possam levar em conta a carga horária das disciplinas e a carga horária do curso, semestre em que as disciplinas são oferecidas e ementas. 


\title{
The teach accounting in Santa Catarina: the curricular matrices of undergraduate courses in review
}

\begin{abstract}
The profile and the formation of professional Accounting depend, in large part of the curriculum offered by educational institutions in their courses of Accounting. Therefore, the study aims to identify the knowledge areas that include the disciplines that make up the curriculum of courses in Accounting offered in the State of Santa Catarina. The methodology used in this research appears as descriptive and documental research conducted by quantitative data analysis. We analyzed the curricular matrices provided by higher education institutions on their websites. The sample consisted of 30 curricular matrices. The results showed that from all disciplines offered by higher education institutions in their Accounting courses, $53.13 \%$ are directly related to the accounting area, $10.07 \%$ from the area of administration, $8.81 \%$ from the area of law, and $5.67 \%$ from the disciplines related to the area of philosophy and sociology. The areas of computer science, psychology, literature and education did not show a significant participation, even taking into account the importance they have for the professional accounting.
\end{abstract}

Keywords: Higher education. Accounting. Curricular matrices.

\section{Enseñanza de contabilidad en Santa Catarina: análisis de las matrices de curriculum en cursos de pregrado}

\section{Resumen}

El perfil y la formación de profesionales de contabilidad dependen en buena parte del currículo que ofrecen las instituciones educativas en sus cursos de contabilidad. Por lo tanto, el estudio tiene como objetivo identificar las áreas de conocimiento que abarcan las disciplinas que conforman el currículo de los cursos de contabilidad que se ofrecen en el estado de Santa Catarina. La metodología utilizada en esta investigación se caracteriza por ser descriptiva, realizada a través de encuestas documental y análisis cuantitativa de los datos. Se analizaron las matrices de currículo que ofrecen las instituciones de educación superior en los sitios. La muestra estuvo constituida por 30 matrices de currículo. Los resultados mostraron que del número total de disciplinas ofrecidos por las instituciones en Cursos de contabilidad 53,13\% están directamente relacionados con el área contable, 10,07\% para el área de administración, 8,81\% para el área de derecho y 5,67\% de las disciplinas son relacionadas con el campo de la filosofía y la sociología. Las áreas de la informática, psicología y la educación no mostraron una participación significativa, incluso teniendo en cuenta la importancia que tienen para el profesional de la contabilidad.

Palabras clave: Educación superior. Contabilidad. Matrices curriculares. 


\section{Referências}

ALTHOFF, N. S.; DOMINGUES, M. J. C. S. Práticas interdisciplinares nos cursos de graduação em Ciências Contábeis: mito ou realidade. In: CONGRESSO ANPCONT, II, 2008, Salvador. Anais... Salvador: BA, 2008.

ARAUJO, A.; O. ARAUJO, M. I. O.; JUNIOR, V. F. M. Percepção sobre a atitude interdisciplinar dos professores no curso de ciências contábeis: Um estudo nas universidades norte rio grandenses. In: CONGRESSO USP DE CONTROLADORIA E CONTABILIDADE, 2009, São Paulo. Anais... São Paulo: USP, 2009.

BERTI, A. Diagnóstico empresarial: teoria e prática. São Paulo: Ícone, 2001.

BRASIL. Ministério da Educação. Instituições de educação superior e cursos cadastrados. Disponível em: < http://emec.mec.gov.br/> Acesso em: 23 out. 2010.

. Ministério da Educação. Parecer CNE/CES 10/2004. Disponível em: < http://emec. mec.gov.br/> Acesso em: 23 out. 2010.

CAPACCHI, M.; MORETTO, C. F.; VANCIN, V.; PADILHA, F. A. R. A prática do ensino contábil no estado do rio grande do sul: Uma análise da grade curricular frente às exigências legais e necessidades acadêmicas. In: CONGRESSO ANPCONT, I, 2007. Gramado. Anais... Gramado: RS, 2007.

CARNEIRO, Juarez Domingues (Coord.). Proposta nacional de conteúdo para o curso de graduação em ciências contábeis. 2. ed. Brasília: Fundação Brasileira de Contabilidade, 2009.

CONSELHO FEDERAL DE CONTABILIDADE. Resolução 560/83. Dispõe sobre as prerrogativas profissionais de que trata o artigo 25 do Decreto-lei n 9.295, de 27 de maio de 1946. Rio de Janeiro, 28 de outubro de 1983.

FIGUEIREDO, S.; FABRI, P. E. Gestão de empresas contábeis. São Paulo: Atlas, 2000.

GIL, A. C. Métodos e técnicas de pesquisa social. 5. ed. São Paulo: Atlas, 1999.

IUDICIBUS, S. Teoria da Contabilidade. 5. ed. São Paulo: Editora Atlas, 2004.

JANTSCH, A. P.; BIANCHETTI, L. Interdisciplinaridade: para além da filosofia do sujeito. 7 ed. Rio de Janeiro: Vozes, 2004.

LAFFIN, M. O professor de contabilidade no contexto de novas exigências. Revista Brasileira de Contabilidade. Brasília, nº 127, 2001.

MARION, J. C. Contabilidade empresarial. São Paulo: Atlas, 2005.

MARION, J. C.; SANTOS, M. C. Os dois lados de uma profissão. 2005. Disponível em: < Www.monografias.com > Acesso em: 23 out. 2010.

MIRANDA, C.; MIRANDA, R. Á. M. Interdisciplinaridade e métodos de ensino no curso de contabilidade: um estudo no Nordeste Paulista. In: CONGRESSO USP DE CONTROLADORIA E CONTABILIDADE, 6, 2006, São Paulo. Anais... São Paulo: USP, 2006, v. 6, p. $1-15$.

OLIVEIRA, A. B. S. (Coord.). Métodos e técnicas de pesquisa em contabilidade. São Paulo: Saraiva, 2003. 
PADOAN, F. A. C.; CLEMENTE, A. A interdisciplinaridade no ensino da Contabilidade: um estudo empírico da percepção dos docentes. In: CONGRESSO USP DE CONTROLADORIA E CONTABILIDADE, 6, 2006, São Paulo. Anais... São Paulo: USP, 2006, v. 6, p. 1-15.

PAVIANI, J.; POZENATO, J. A universidade em debate. Caxias do Sul: Editora da Universidade de Caxias do Sul, 1984.

PORTO, C.; REGNIER, K. O ensino superior no mundo e no brasil: condicionantes, tendências e cenários para o horizonte 2003-2025. Brasília, Distrito Federal, 2003. Disponível em: < http://portal.mec.gov.br/sesu/arquivos/pdf/ensinosuperiormundobrasiltende nciascenarios2003-2025.pdf >. Acesso em: 23 out. 2010.

RICHARDSON, Roberto Jarry. Pesquisa social: métodos e técnicas. 2. ed. São Paulo: Atlas, 1989.

ROESCH, S. Projetos de estágio e de pesquisa em administração. 2. ed. São Paulo: Atlas, 1999 .

ROSELLA, M. H. et. al. O ensino superior no Brasil e o ensino da contabilidade. In: PELEIAS, I. R. (Org.). Didática do ensino da contabilidade: aplicável a outros cursos superiores. São Paulo: Saraiva, 2006.

SCHLINDWEIN, A. C. O ensino de Ciências Contábeis nas Instituições de Ensino da Mesorregião do Vale do Itajaí/SC: uma análise das contribuições curriculares da Resolução CNE/CES N. 10/2004. 2007. Dissertação (Mestrado em Ciências Contábeis) - Curso de Pós-Graduação em Ciências, Universidade Regional de Blumenau, Blumenau, 2007.

SERRA NEGRA, C. A. Reflexões sobre os quatro pilares da educação no ensino superior de ciências contábeis. Revista do Conselho Regional de Contabilidade do Rio Grande do Sul, Porto Alegre, v. 3, n. 118, p. 6-14, out. 2004, .

SILVA, M. B. de; GRIGOLO, T. M. Metodologia da pesquisa e elaboração de dissertação. Florianópolis: EDUFSC, 2001.

VENTURI, J. et al. Satisfação dos alunos do curso de ciências contábeis da Unifra: um estudo à luz das equações estruturais. In: CONGRESSO USP DE CONTROLADORIA E CONTABILIDADE, 8, 2008, São Paulo. Anais... São Paulo: USP, 2008.

WATSON, S. F. et al. Accounting education literature review (2003-2005). Journal of Accounting Education. United States, n. 25, 2005. 